\title{
Effect of Different Cryoprotectants in Cryopreservation of Dog Semen: A Review
}

\author{
Kaushal Kusum $^{1 *}$, Harendra Kumar ${ }^{2}$, Raghavendra P. Mishra ${ }^{3}$, Brajesh Kumar ${ }^{4}$ and Saurbh $^{5}$ \\ ${ }^{1}$ Division of Animal Reproduction, ICAR-Indian Veterinary Research Institute (IVRI), Izatnagar, Bareilly, U.P., INDIA \\ ${ }^{2}$ Head of division: Division of Animal Reproduction, ICAR-Indian Veterinary Research Institute (IVRI), Izzatnagar, \\ Bareilly, U.P., INDIA \\ ${ }^{3}$ Department of Veterinary Public Health, Apollo College of Veterinary Medicine, Jaipur, Rajasthan, INDIA \\ ${ }^{4}$ Department of Veterinary Pathology, Apollo College of Veterinary Medicine, Jaipur, Rajasthan, INDIA \\ ${ }^{5}$ Department of Livestock Farm Complex, Apollo College of Veterinary Medicine, Jaipur, INDIA \\ "Correspondence author: K Kusum; E-mail: kusumkaushal197@gmail.com
}

Received: 20 June, 2020

Revised: 05 Nov., 2020

Accepted: 15 Nov., 2020

\begin{abstract}
Several canine practitioners are facing limited success in canine artificial insemination using poorly assessed frozen dog semen due to unestablished set of semen evaluating parameters and semen diluents. The types of cryoprotectants plays import role in formulation of good semen diluents in canine semen cryopreservation which limits spermatozoa structure and viability in assisted reproductive technology. The cryopreservation process causes change in osmotic pressure and ice formation in spermatozoa which lead to cryoinjury and loss of viability and membrane integrity in post-thaw spermatozoa. This causes poor sperm quality and so poor fertility. The efficient cryoprotectants are those which penetrate deeper of spermatozoa and non-toxic. Glycerol and ethylene glycol are the most commonly used cryoprotectant for dog spermatozoa and other cryoprotective agents have been tested only sporadically. Hence, selection of better cryoprotectants based semen diluents and evaluation parameters of post-thaw semen is very much important for successful canine breeding to achieve dissemination of genetic material even after death, overcome quarantine restrictions, prevent venereal infections and semen exchange without moving stud dogs for breeding, etc. Therefore, establishing an efficient cryopreservation technique for dog sperm would be an essential resource for better dog breeding systems. The present article present the details reviews on cryopreservation of dog semen, different cryoprotectants and semen evaluation parameters for determining better production of quality dog semen.
\end{abstract}

\section{HIGHLIGHTS}

(0 Cryopreservation helps to preserve semen to the long period of time.

(0 Cryoprotectants includes all the required constutuents which protects the sperms from several sperm abnormalities.

Keywords: Cryopreservation, DNA integrity, Dog, Semen

The fertility data with the use of cryopreserved semen are still scarce, preventing the homogenous evaluation and there is standardization of the technique for dogs (Farstad, 2009). The semen cryopreservation in canine has gain importance in modern days for efficient assisted reproductivetechnologyincaninebreeding(Thomassenand Farstad, 2009; Milani et al., 2010; Leroy et al., 2011), thus reduces transportation cost. The success of insemination is closely related to the semen quality and evaluation of suitable parameters representing spermatozoal integrity and viability. The semen cryopreservation leads to the production of Reactive Oxygen Species (ROS) by the spermatozoa and causing oxidative stress of sperm cells, which is necessary for sperm capacitation and, therefore, fertilization (Lenzi et al., 2002). However, oxidative stress can be premature during the cryopreservation process (Halliwell, 1991; Sharma et al., 2012), carbohydrate

How to cite this article: Kusum, K., Kumar, H., Mishra, R.P., Kumar, B. and Saurbh (2020). Effect of different cryoprotectants in cryopreservation of dog semen: A review. J. Anim. Res., 10(6): 859-867. Source of Support: None; Conflict of Interest: None 
moieties alternating proteins, sperm motility, plasma membrane functionality, and sperm DNA (Birben et al., 2012). The damage induced by cryopreservation on spermatozoa is multimodal because in several studies there was a combination of cold shock, peroxidation (Slaweta et al., 1988) and osmotic stress (Watson, 2000). Further, the temperature reduction is beyond the freezing point for semen, water forms ice crystals first in the extracellular compartment. This increases the solute concentration in the free uncrystallised water outside the cell, inducing hyperosmotic stress. During thawing, however, the ice crystals melt in the free water that enters the plasma membrane, thus sperm undergo hypo-osmotic stress (Sieme et al., 2016). Hence, cryopreservation may promote loss of membrane integrity, decreased sperm motility and sperm DNA damage (Lucio et al., 2017). Consequently, various studies were undertaken to examine various cryoprotectants to improve sperm quality by preventing the ROS attack during cryopreservation (Bilodeau et al., 2001; Keskes-Ammar et al., 2003; Domoslawska et al., 2013; Manson and Rous 2014; Romagnoli and Lopate, 2014). The semen extender is a necessary substance for semen cryopreservation, as it has the function to maintain cell membrane stability due to its buffer property, controlling the $\mathrm{pH} 7$ and there are provided the electrolyte balance and osmolarity to the medium (Eilts, 2005). Therefore, selection of better cryoprotectants supplemented semen extender play important role in protecting spermatozoal integrity and viability during cryopreservation. The permeability of cryoprotectant is likely to be different among species since it depends on the structure and composition of the spermatozoal membrane mechanism (Rota et al., 2006; Shalini et al., 2018). The four types of cryoprotectants viz glycerol, ethylene glycol, DMSO (dimethyl sulfoxide), and propanediol has been chiefly used for dog semen. However, Said et al., (2010) was used dimethyl formamide and different level of glycerol and ethylene glycol. Ethylene glycol had better result, because, it penetrate more quickly in the tissue, probably due to its lower molecular weight. Candy et al., (1997) reported that the ethylene glycol is highly permeable and less toxic than glycerol. Ethylene glycol permeability was found to be higher than glycerol permeability in spermatozoa. Among them, glycerol and ethylene glycol has been used as a more suitable cryoprotectant (Bessa et al., 2006). Ethylene glycol has highest permeability in human (Gilmore et al., 1998) and mouse (Phelps et al., 1999) spermatozoa. This paper also reviewed the suitable spermatozoal quality parameters to be assessed for quality check of semen membrane integrity and viability viz. post-thaw longevity, motility parameters and plasma membrane functional integrity through the Hypo-osmotic sperm swelling test and DNA integrity (Kusum et al., 2012 ; Choudhary et al., 2016; Mango et al., 2019).

\section{Effect of different cryoprotectants on dog spermatozoa}

There are constituted of sperm extenders by extracellular cryoprotectant (Milk and egg yolk) and intracellular Cryoprotectant (Ethylene glycol, glycerol or dimethyl sulfoxide), or other agents are included buffer agent (tris), sugar (sucrose, lactose, glucose fructose), salts (Sodium citrate and citric acid) and antibiotics (Streptomycin, Amikacin Penicillin). The several extenders recommended for semen cryopreservation in the canine species, such as soya lecithin, decreased density lipoproteins (LDL), reduced glutathione, milk, liposomes and the powder coconut water (Kmenta et al., 2011; Ogata et al., 2015; Lucio et al., 2017; Belala et al., 2016; Das et al., 2018).

Watson (1979) reported that addition of higher concentration of glycerol may also affect the fertilizing capacity of spermatozoa. Olar (1989) found that the postthaw motility was higher when 3-4 percent glycerol was used in an egg-yolk Tris-based diluent. Although, Smith (1984) found that 9 percent glycerol in an egg-yolk-pipes extender was optimal., In cryopreservation of dog semen, concentration of glycerol have been added to varying levels of 2 and 5 (Olar et al., 1989); 6 percent (Nair, 1996). This decreased sperm motility was reduced when glycerol was initially incorporated in the extender compared to its addition after cooling. The addition of 8 percent $\mathrm{v} / \mathrm{v}$ glycerolated extender (final glycerol concentration 4 percent) compared to no glycerol addition, had shown to cause a decrease in the number of sperm penetrating homologous oocytes after pre-freeze cooling (Hay et al., 1997). Pereira et al. (2002) also found temperature of glycerol addition had no effect on post-thaw sperm quality, however, they found that both post-thaw motility and acrosomal integrity were superior following use of 8 percent glycerolated extender compared to 2,4 and 6 percent Gharajelar et al. (2016).

Silva et al. (2003) compared the effect of single and fractionated glycerol on cryopreservation of dog semen 
and reported that the single method of glycerol addition found to be easier and most practical to use than the addition of fractionated glycerol. Alvarez and Story (1993) reported that the effects of ethylene glycol as cryoprotectants may be species specific. Ethylene glycol and glycerol are different cryoprotectants due to difference in their permeability coefficient. Storrey et al. (1998) reported that chemical structure of glycerol and ethylene glycol are quite similar, having the same ratio of carbon atoms and hydroxyl groups which is the indication of molecule lipophilia and hydrophilia. Ethylene glycol and glycerol is consistent with the measure permeability of these cryoprotectants as reported in boar (Gilmore et al., 1998) and mouse (Phelps et al., 1999) spermatozoa in those species in which estimate the permeability. The permeability of ethylene glycol is approximately 1.53 times that of glycerol. Pantano (2000) reported that Ethylene glycol minimizes the detrimental effect of the dehydration and rehydration during the freezing and thawing processes. Spermatozoa had a higher osmotic tolerance to quick addition and removal of ethylene glycol than to the glycerol. Massip (2001) reported that ethylene glycol has smaller molecular weight, a characteristic that may result in lower toxicity and higher permeability to cell. Ball (2001) reported the possibility of ethylene glycol could cause less osmotic lesions has already been suggested for stallion spermatozoa. Guthrie et al. (2002) observed the effects of using ethylene glycol in frozen thawed semen varied among species with bull semen. Ethylene glycol resulted in higher post thaw motility when compared with glycerol because of reduction of the osmotic lesions. Pereira et al. (2002) reported that ethylene glycol can readily cross cell membrane and hence penetrate and leave the cell faster than glycerol. Mantovani et al. (2002) when used to cryopreserve stallion semen observed that ethylene glycol had similar results to those of glycerol, and successfully replaced it when used in same or lower concentrations. Petrunkina et al. (2004) reported that dog sperm volume response to osmotic shock is regulated by the activity of potassium channel and in minimized by the presence of an intact cytoskeleton. Ethylene glycol might affect the functionality of potassium channel, their activation mechanism of fluxes of ions and organic osmolytes. Spermatozoa show different volumetric variations under similar hypo osmatic condition, reflecting individual difference in cytoskeleton characteristic and potassium channel activity. Rota et al. (2006) reported that progressive motility was significantly higher in ethylene glycol samples than post thaw dog spermatozoa. Ethylene glycol showed higher path velocity and increased straight line velocity. However, ethylene glycol semen samples also showed higher curvilinear velocity, which may indicate a capacitation like condition affecting sperm membranes and possibility of reducing post thaw longevity. Bessa et al. (2006) reported the combination of 4 percent ethylene glycol and 4 percent glycerol maintains sperm motility, viability and acrosomal integrity, respectively. Alvarez and Story (1993) observed the effect of ethylene glycol as a suitable cryoprotectant which was species specific. In our study, ethylene glycol showed higher motility because ethylene glycol penetrated more quickly than glycerol (Newton et al., 1996). Ethylene glycol is highly permeable and less toxic than glycerol. Ethylene glycol and glycerol are different cryoprotectant due to variation in their permeability coefficient (Candy et al., 1997).

Chemical structure of glycerol and ethylene glycol are quite similar, having the same ratio of carbon atoms and hydroxyl groups which is the indication of molecule lipophilia and hydrophilia (Storrey et al., 1998). Ethylene glycol and glycerol are consistent with the measure permeability as reported in boar (Gilmore et al., 1998) and mouse (Phelps et al., 1999) spermatozoa. The permeability of ethylene glycol is approximately 1.5-3 times more to that of glycerol. Ethylene glycol minimizes the detrimental effect of the dehydration and rehydration during the freezing and thawing processes (Pantano et al., 2000). Spermatozoa had a higher osmotic tolerance to quick addition and removal of ethylene glycol than to the glycerol. Ethylene glycol has smaller molecular weight, a characteristic that may result in lower toxicity and higher permeability to cell (Massip, 2001). The effects of using ethylene glycol in frozen thawed semen varied among species. Ethylene glycol can readily cross cell membrane and hence penetrate and leave the cell faster than glycerol (Pereira et al., 2002). Dog sperm volume response to osmotic shock is regulated by the activity of potassium channel and is minimized by the presence of an intact cytoskeleton. Ethylene glycol might affect the functionality of potassium channel, their activation mechanism of fluxes of ions and organic osmolytes. Spermatozoa showed different volumetric variations under similar hypoosmatic condition, reflecting individual difference in cytoskeleton characteristic and potassium 
channel activity (Petrinkina et al., 2004). Addition of 5 percent ethylene glycol as a cryoprotectant resulted in 63 percent post-thaw motility in canine semen (Rota, 2006). Ethylene glycol showed increase path velocity and there is higher straight line velocity. However, ethylene glycol semen samples also showed higher curvilinear velocity, which may indicate a capacitation like condition affecting sperm membranes and possibility of reducing post-thaw longevity. The combination of 4 percent ethylene glycol and 4 percent glycerol maintain sperm motility, viability and acrosomal integrity (Bessa et al., 2006; Mota, 2014).

The addition of 8 percent glycerolated extender at $5^{\circ} \mathrm{C}$, compared to 4 percent glycerol, had shown to be more harmful to domestic dog sperm longevity, when held at $5^{\circ} \mathrm{C}$. The addition of higher concentration of glycerol may also affect the fertilizing capacity of spermatozoa (Watson, 1979). Olar et al. (1989) found that the post-thaw motility was higher when 3-4 percent glycerol was used in an eggyolk Tris-based diluent. Although, Smith (1984) found that 9 percent glycerol in an egg-yolk-pipes extender it was optimal. In cryopreservation of dog semen, concentration of glycerol has been added to varying levels of 2, 5 and 6 percent (Nair, 1996). The decreased sperm motility was reduced when glycerol was initially incorporated in the extender compared to its addition after cooling. The addition of 8 percent $\mathrm{v} / \mathrm{v}$ glycerolated extender (final glycerol concentration 4 percent) compared to no glycerol addition, had shown to cause a decrease in the number of sperm penetrating homologous oocytes after pre-freeze cooling (Hay et al., 1997). Pereira (2002) also found that the temperature of glycerol addition had no effect on postthaw sperm quality and both the post-thaw motility and the acrosomal integrity were superior following the use of 8 percent glycerolated extender compared to 2, 4 and 6 percent. A single method of glycerol addition found to be easier and most practical to use than the addition of fractionated glycerol (Silva et al., 2003; Shalini and Antoine, 2018).

The value of dog spermatozoa livability as observed in four different group of cryoprotectant in post-thaw spermatozoa was in the range of $55.23 \pm 2.21$ to 57.00 \pm 1.60 percent (Kusum et al., 2012). Pefia et al., (1999); Cordoso et al. (2003) and Pena (2003), reported almost similar report. The values were lower than that recorded by Pefia et al. (1999) and Kurien (2012) who used 6 to 8 percent glycerol levels and relatively higher than reported by Verstegen et al. (2005). These variations might be due to the use of different cryoprotectants and the method of freezing.

\section{Evaluation of Important Parameters of Frozen Semen}

\section{Post-thaw motility}

The value of post-thaw motility in canine semen with 5 percent ethylene glycol as cryoprotectants was recorded as $36.83 \pm 1.26$ and with 4 percent and 8 percent glycerol and was $32.75 \pm 1.88$ and $28.50 \pm 0.81$, respectively (Kusum et al., 2012). While 4 percent glycerol and 4 percent ethylene glycol showed 29.25 percent similar findings were reported by Kurien (2000). Morton and Bruce (1989) obtained 41 percent post-thaw motility in frozen thawed dog semen, while Dobrinski et al. (1993) recorded 32.2 $\pm 1.5,33.7 \pm$ $1.6,30.9 \pm 1.6$ and $30.3 \pm 1.4$ percent post-thaw motility in Triladyl, Pipes, IMV Universal and Tris extenders, respectively. Nothling and Volkmann (1993) recorded post-thaw 35 percent motility in Triladyl extender while, Silva and Verstegen (1995) observed post-thaw motility of 65, 65 and 50 percent in Laiciphos, Tris and Baciphos extenders respectively. Strom et al., (1997) recorded 69.7 \pm 8.2 and $73.7 \pm 3.2$ percent post-thaw motility at $37^{\circ} \mathrm{C}$ in Anderson and Clone methods of semen cryopreservation whereas (Pefia et al., 1999) observed $33.6 \pm 16.2$ and $60.0 \pm 8.2$ per cent post-thaw motility in 6 and 8 percent glycerol levels, respectively.

Whereas, Kurien (2000) obtained the average post-thaw live sperm percentage of $39.56 \pm 1.0,37.43 \pm 1.08$ and $31.01 \pm 0.68$ in Tris, Trialdyl and Laiaphas - 488 extenders respectively. Pena et al. (2003) obtained $54.6 \pm 10.7$ percent of live spermatozoa in frozen thawed dog semen. Cardoso et al. (2003) found dog spermatozoa motility after thawing $49.2 \pm 26.0,44.2 \pm 18.3$ and $35.8 \pm 26.8$ percent for three groups with 4, 6 and 8 percent glycerol respectively. Nizanskin (2006) reported $49.5 \pm 8.1$ percent progressive motility in frozen thawed dog spermatozoa added with 4 percent glycerol. Rota et al. (2006) observed that progressive motility was significantly higher with ethylene glycol than glycerol $(51.5 \pm 4.7$ percent and 31 \pm 5.6 percent). According to earlier report of Strom et al., (1997) who recorded 69.7 and 73.7 percent post-thaw motility at $37^{\circ} \mathrm{C}$ in Anderson and clone methods of semen cryopreservation. Whereas, Pefia et al. (1999) observed 
60.0 percent post thaw motility in 6 and 8 percent glycerol level, respectively.

\section{Abnormal spermatozoa}

The value of abnormal spermatozoa in dog semen estimated in different groups of cryoprotectants ranged from $25.42 \pm 0.80$ to $28.83 \pm 1.92$ percent. Nair (1996) observed post-thaw abnormality of $35.84 \pm 1.64$ and $42.74 \pm 1.15$ percent in 9 and 6 per cent glycerol levels, respectively. Kurien (2012) recorded an average postthaw abnormal sperm percentage of $18.73 \pm 0.17,18.98 \pm$ 0.15 and $19.60 \pm 0.16$ in Tris, Triladyl and Laiciphos-488 extenders, respectively, whereas, Silva et al., (2003) obtained $24.9 \pm 20.0$ percentage of abnormal sperm in frozen thawed semen.

The normal and abnormal spermatozoa morphology completely depends up on the phase of spermatogenesis, where spermatid is converted to spermatozoa. It is regulated by sertoli cells which are the only non-germinal cell in the seminiferous tubules. Sertoli cells regulate the acrosomal phase of spermatogenesis where there is condensation and elongation of nucleous and acrosome and some minor changes in tail portion occurs. So any alteration in sertoli cell structure or function may affect morphology of sperm Medeiros et al. (2002).

\section{Hypo-osmotic swelling test (HOST)}

HOST response measures the membrane integrity and membrane stabilizing action of spermatozoa. The mean value of HOST response observed in all cryoprotectants was in the range of 45.33 to 51.50 . It is a known fact that sperm motility and viability is dependent upon membrane transport. These facts find support from the result of present study in which higher motility and viability was observed. The plasma membrane is regarded as the primary site of freezing injury and the types of damage depends on different freezing conditions. Kurien (2000) observed an average hypo-osmotic swelling response as $49.88 \pm 0.71,48.05 \pm 0.90$ and $43.03 \pm 0.57$ percent in Tris, Triladyl and Laiciphos-488 extenders respectively in Mongrel dog semen. Fertilization will not occur, if the sperm membrane is physically intact, but is inactive biochemically. Therefore, HOS test could be regarded as more conclusive method to detect membrane integrity and fertilizability of spermatozoa (Thundathil, 2002). Ponglowhapan et al. (2004) obtained the mean percentage of $54.2 \pm 6.7$ damaged plasma membrane in frozen thawed dog semen. During the HOS test, spermatozoa with a biochemically active plasma membrane, when exposed to the hypo-osmotic solution, will increase in volume due to intracellular influx of water, which is the sign of membrane integrity and normal activity of spermatozoa (Dobrinski et al., 1993; Rota et al., 2006; Cheema, 2012).

\section{Acrosomal integrity}

Kurien (2000) recorded an average post-thaw intact acrosome percentage of $64.78 \pm 0.33,64.43 \pm 0.26$ and $62.86 \pm 0.41$ in Tris, Triladyl and Laiciphos-488 extenders, respectively in Mongrel dog semen. Yildizet al., (2000) obtained the mean percentage of $44.6 \pm 3.2$ and $47.9 \pm 3.1$ damaged acrosome in frozen thawed semen using fructose and glucose, respectively. Ponglowhapan et al. (2004) reported $34.7 \pm 15.0$ percentage of acrosomal loss in frozen semen. Umamageswari (2005) showed post-thaw acrosomal integrity 46 percent.

Ultra structurally, cold shock is manifested by loss of selective permeability and integrity of plasma membrane, release of intracellular enzymes and lipids from the spermatozoa and there after loss of motility and diminished metabolism. Therefore, a more complete assessment of function was obtained by evaluating spermatozoal motility, membrane integrity and acrosomal morphology in this study. Mammalian sperm are very sensitive to cooling from body temperature to freezing. Damage to sperm due to freezing known as cold shock was observed as an irreversible loss of motility (Medeiros et al., 2002).

\section{DNA integrity}

DNA integrity of spermatozoa (Double strand breaks) was estimated by single cell alkaline micro gel electrophoresis method (comet assay) as described by Singh et al. (2003). Cryopreservation is widely used in many assisted conception unit to preserve male fertility (Aitken, 1995; Serafini et al., 2017; Ferreira et al., 2018). Maintenance of sperm DNA integrity is crucial to the health of future generations (Evenson, 1999; Hamilton et al., 2019). In contrast to the relatively dormant female gametes, spermatozoa are produced by the testes as male germ cells 
and there are undergo lifelong cell replication, meiosis and spermiogenesis. Male gametes as corresponds to female gametes have a greater possibility of damage to nuclear DNA of Y chromosomes. This is due to lack of recombination repair process, as there is only one $\mathrm{Y}$ chromosome available during meiosis (Ward Zalelsky, 1996; Aitken, 2011; Stuart et al., 2019). Therefore, analysis of spermatozoa for DNA integrity is more important before freezing and thawed DNA damage does occur in both developing and mature sperm. So, high proportion of sperm with DNA damage might be a cause of infertility in animals (Shen et al., 1999). Although, ideally the healthiest sperm (with intact DNA) will fertilize the ovum, sperm with damaged DNA may accomplish fertilization, this might be the reason of poor pregnancy outcome (Wdowiak et al., 2015).

Sperm membrane disruption caused during cryopreservation may be a consequence of liquid phase transition change and lipid peroxidation (LPO) and further lead to DNA damage due to oxidative stress (Alverage and Storey, 1993). Sperm head mainly comprise the sperm DNA, so change in sperm morphology may be related to abnormal DNA content (Martinez et al., 2005; Gloria et al., 2018). Macias (2006) also reported low DNA integrity due to freezing-thawing process in dog spermatozoa. In recent days, there is a burgeoning interest in the implication of spermatozoal DNA damage during semen preservation. As DNA fragmentation of animal spermatozoa was negatively correlated with fertilization, as it did not preclude pronucleous formation after ovum penetration (Macias et al., 2006).

Therefore, assessment of spermatozoal DNA integrity is a necessary requirement for selection of better cryoprotectants and a thorough knowledge of spermatozoa achieving capacity in fertilization and embryo development (Evenson et al., 1999; Cho and Agarwal, 2018). The ethylene glycol showed higher percentage of intact DNA in frozen semen. High DNA intactness in ethylene glycol as compared to other cryoprotectants might have caused less LPO so reduced the effect of oxidative stress on DNA damage (Baumer et al., 2003; shahoo et al., 2015). This might be due to more stability of spermatozoal membrane and less toxicity of ethylene glycol to spermatozoa (Candy et al., 1997; Samoylova, 2010).

\section{CONCLUSION}

This reviews article on different cryoprotectants for canine semen preservation revealed ethylene glycol is better as compared to other cryoprotectants. Further, post thaw semen evaluation should include batch wise testing for spermatozoal DNA integrity, membrane integrity, progressive motility, and viability to assess efficiency of semen diluents. However, more studies are required to establish universal semen extender for different breeds of dogs.

\section{ACKNOWLEDGEMENTS}

Author solemnly acknowledges the Animal Husbandry Department, Patna, Govt. of Bihar for necessary permission to pursue doctoral research on canine reproduction. I am thankful to ICAR-Indian Veterinary Research Institute, Izatnagar for providing financial assistance in the shape of Institute Senior Research Fellowship. I also acknowledge the tireless efforts of our lab and kennel assistants.

\section{REFERENCES}

Aitken, R.J. 1995. Free radicals, lipid peroxidation and sperm function. Reprod. Fertil. Dev., 7: 659-68.

Aitken, R.J. 2011. The capacitation-apoptosis highway: oxysterols and mammalian sperm function, Biol. Reprod., 85: 9-12.

Alvarez, J.G and Storey, B. 1993. Evidence that membrane stress contributes more than lipid peroxidation to sublethal cryodamage in cryopreserved human sperm-glycerol and other cryoprotectant, J. Androl., 14: 199-209.

Ball, B.A. 2001. Osmotic tolerance of equine spermatozoa and the effect of soluble cryoptrotectant on equine sperm motility viability and mitochondrial membrane potential, J. Androl., 22: 1061-1069.

Baumer, J., Ball, A.B., Jermer, J. and Meyers, A.S. 2003. Reactive oxygen species and cryopreservation promote DNA fragmentation in equine spermatozoa, J. Androl., 29: 621628.

Belala, R., Briand-Amirat, L., Vinciguerra, L., Tainturier, D., Kaidi, R., Thorin, C., Anton, M. and Bencharif, D. 2016. Effect of equilibration time on the motility and functional integrity of canine spermatozoa frozen in three different extenders. Res. Vet. Sci., 106: 66-73.

Bessa, A.M., Rocha, A. and Aguirre, A.M. 2006. Comprising ethylene glycol with glycerol for cryopreservation of canine semen in egg-yoil tris extenders. Theriogenology., 66(9): 2047-2055. 
Bilodeau, J.F., Blanchette, S., Gagnon, C. and Sirardm, M.A. 2001. Thiols prevent $\mathrm{H}_{2} \mathrm{O}_{2}$-mediated loss of sperm motility in cryopreserved bull semen. Theriogenology, 56: 275-286.

Birben, E., Sahiner, U.M., Sackesen, C., Erzurum, S. and Kalayci, O. 2012. Oxidative stress and antioxidant defense. World Allergy Organization J., 5(1): 9-19.

Candy, C.J., Wood, M.J. and Whittingham, D.G. 1997. Effect of cryoprotectant on the survival of follicles in frozen mouse ovaries. J. Reprod. Fertil., 9: 2334-2338.

Cardoso, R.C., Silva, A.R., Uchoa, D.L. and Silva, D.M. 2003. Cryopreservation of canine semen using a coconut water extender with egg yolk and these different glycerol concentration, Theriogenology, 53: 743-757.

Cheema, R.S.,Vashishat, N., Bhakri, G. and Gandotra, V. 2012. Characterization of antigenic proteins in dog spermatozoa and effect of immunization with sperm membrane proteins on semen quality. Theriogenology, 2: 13-31.

Cho, C.L. and Agarwal, A. 2018. Role of sperm DNA fragmentation in male factor infertility: a systematic review. Arab J. Urol., 16:21-34.

Choudhary, K.K., Kavya, K.M., Jerome, A. and Sharma, R.K. 2016. Advances in reproductive biotechnologies. Vet. World, 9: 388-395.

Das, A., Biswas, R.K., Deka, B.C. and Dutta, J. 2018 .Quality of Labrador- Retriever dog semen on short-term preservation in different extenders. J. Anim. Res., 2(52): $220-225$

Dobrinski, I., Lulai, C., Barth, and Past, K. 1993. Effects of four different extenders and three different freezing rates on postthaw viability of dog semen. J. Reprod. Fertil., 47: 291-296.

Domosławska, A., Sławomir, Z.K., Niżańskil, W. and Tomasz, J. 2013. Assessment of semen size, daily production and output of spermatozoa and extragonadal spermatozoa reserves of the dog. Biol. Reprod., 29: 1114-1120.

Eilts, B.E. 2005. Thoretical aspects of canine semen cyropreservation. Theriogenology, 64: 692-697.

Evenson, D.P., Jost, L.K., Marshall, D., Hinaman, M.J., Ctegg, E. and Purvis, K. 1999. Utility of the sperm chromatin assay as a diagnostic and progostic tool in the human fertility clinic. Hum. Reprod., 14: 1039-1049.

Farstad, W. 2009. Cryopreservation of canine semen - new challenges. Reproduction in Domestic Animals, 44(Supp1 2): 336-341.

Ferreira, H.N., Ferreira-Silva, J.C., Rocha, J.M., Farras, M.C., Calixto, M., Moura, M.T, Alvarenga, M.A. and Oliveira, A.L. 2018. Variable inter-assay estimation of sperm DNA fragmentation in stallions classified as good and bad semen freezers. Cryo. Lett., 39: 67-71.
Gharajelar, S.N., Sardrkhaloo, R., Onsori, M. and Saderivand, A. 2016. A Comparative study on the effects of different cryoprotectants on the quality of canine sperm during vitrification process. Vet. Res. Forum., 7(3): 235-239.

Gilmore, J.A., Liu, J., Peter, A.T. and Crister, J.K. 1998. Determination of plasma membrane characteristics of boar spermatozoa and theire relevance to cryopreservation. Biol. Reprod., 12: 112-118.

Gloria, A., Wegher, L., Carluccio, A., Valorz, C., Robbe, D. and Contri, A. 2018. Factors affecting staining to discriminate between bull sperm with greater and lesser mitochondrial membrane potential. Anim. Reprod. Sci., 189: 51-59.

Guthrie, H.D., Liu, J. and Critser, J.K. 2002. Osmotic tolerance limit and effects of cryoprotectants on motility of bovine spermatozoa. Biol. Reprod., 67: 1061-1069.

Halliwell, B. 1991. Reactive oxygen species in living systems. source, biochemistry, and role in human disease. Am. J. Med., 91: S14-S22.

Hamilton, T.R.S., Simoes, R., Mendes, C.M., Goissis, M.D., Nakajima, E., Martins, E.A., Visintin, J.J.A. and Assumpção, M.E. 2019. Detection of protamine 2 in bovine spermatozoa and testicles. J. Androl., 7: 373-81.

Hay, M.A., King, W.A., Gartley, C.J., Leibo, S.P. and Goodrowe, K.L. 1997. Effect of cooling freezing and glycerol on perfration of oocytes by spermatozoa in dog. J. Reprod. Fertil., 51: 99-108.

Keskes-Ammar, L., Feki-Chakroun, N., Rebai, T., Sahnoun, Z., Ghozzi, H., Hammami, S., Zghal, K., Fki, H., Damak, J. and Bahloul, A. 2003. Sperm oxidative stress and the effect of an oral vitamin $\mathrm{E}$ and selenium supplement on semen quality in infertile men. Archi. Androl., 49: 83-94.

Kmenta, I., Strohmayer, C., Muller-Schlosser, F. and SchaferSomi, S. 2011. Effects of a lecithin and catalase containing semen extender and a second dilution with different enhancing buffers on the quality of cold-stored canine spermatozoa. Theriogenology., 75: 1095-1103.

Kurien, M.O. 2000. Cryopreservation of dog semen with different extenders and assessment of freez ability by various semen evaluation methods. Ph.D. Thesis submitted to TANUVAS, Chennai-51, India.

Kurien, M.O., Katheresan, D., Selvaraju, M., Elvaraju, and Pattabiraman, S.R. 2012. Macroscopic, microscopic and biochemical characteristics of fresh dog semen. Indian J. Anim. Reprod., 33(1): 18-20.

Kusum, K., Ansari, M.R. and Roy, R.K. 2012. Effect of Cryoprotectants on Viability of canine spermatozoa. Indian Vet. J., 89(10): 11- 14.

Kusum, K., Roy, R.K. and Ghosh, S.K. 2012. Influence of Cryoprotectants on Integrity of Frozen Thawed canine spermatozoa. Indian Vet. J., 89(11): 139- 140. 
Lenzi, A., Gandini, L., Lombardo, F., Picardo, M., Maresca, V., Panfili, E., Tramer, F., Boitani, C. and Dondero, F. 2002. Polyunsaturated fatty acids of germ cell membranes, glutathione and blutathione-dependent enzyme-PHGPx. from basic to clinic. Contraception, 65: 301-304.

Leroy, G., Danchin-Burge, C. and Verrier, E. 2011. Impact of the use of cryobank samples in a selected cattle breed: a simulation study. Genetics Selection Evolution, 43(1)36.

Lucio, C.F., Angrimani, D.S.R. and Brito, M.M. 2017. Vannucchi CI.2017. Oxidative stress and sperm cryopreservation in dogs. J. Vet. Androl., 2(1): 1-7.

Macias, V.G., Paster, M., Garde, M.V., Anel, E. and Paz, P.D. 2006. Assessment of chromatin status (SCSA) in epididymal and ejaculated sperm in Ibarian red deer, ram and domestic dog. Theriogenology., 66: 1921-1930.

Mang, G.M., Gonzales, M.M., Hidalgo, R.M., Mallma, J.M., Betar, J.R., Palma, V.R. and Sales, E.M. 2019. Effect of Extender and Freezing Rate on Quality Parameters and In Vitro Fertilization Capacity of Alpaca Spermatozoa Recovered from Cauda Epididymis. Biopres. Biobank., 17: $39-45$.

Mantovani, R., Rota, A., Falomo, M.E, Bailoni, L. and Vincenti, L. 2002. Comparison between glycerol and ethylene glycol for the cryopresrvation of canine spermatozoa. Sperm quality assessment with standard analyses and with the hypo-osmotic swelling test. Reprod. Nutri. Devlop., 42: 217-226.

Martinez, I.N., Moran, I.M. and Pena, A. 2005. Do computer assisted morphonitriz derived sperm characteritics reflect DNA status in canine spermatozoa. Reprod. Domes. Ani., 40(6): 537.

Mason, S.J. and Rous, N.R. 2014. Comparison of endoscopicassisted transcervical and laparotomy insemination with frozen-thawed dog semen. a retrospective clinical study. Theriogenology., 82: 844-850.

Massip, A. 2001. Cryopreservation of embryo of farm animals. Reprod. Domes. Ani., 36: 49-55.

Medeiros, C.M.O., Forell, F., Oliveira, A.T.D. and Rodrigues, J.L. 2002. Current status of sperm cryopreservation: why isn't it better. Theriogenology., 57:327-44.

Milani, C., Fontbonne, A., Sellem, E., Stelletta, C., Gerard, O. and Romagnoli, S. 2010 Effect of post-thaw dilution with caffeine, pentoxifylline, 2'-deoxyadenosine and prostatic fluid on motility of frozen-thawed dog semen. Theriogenology, 74: 153- 164.

Mota, A.C., Silva, V.R., Nunes, T.G.P., Souza, M.B., Freitas, L.A, Araujo, A.A. and Silva, L.D.M. 2014. Cryopreservation of canine epididymal sperm using ACP-106c and TRIS. Cryobiology, 69: 17-21.
Nair, S.R.M. 1996. Viability and membrane integrity of cryopreserved dog semen. M.V.Sc. Thesis submitted to TANUVAS, Chennai, India.

Newton, H., Aubard., Rutherford, A., Sharm, V. and Gosden, R. 1996. Cow temperature storage and grafting of human ovarian tissue. Hum. Reprod., 11: 1487-1491.

Nothling, J.O. and Valkman, D.H. 1993. Effect of addition of autologour prostatic fluid on the fertility of frozen-thawed dog-semen after intravaginal insemination. J. Reprod. Fertil., 47: 329-333.

Ogata, K., Sasaki, A., Kato, Y., Takeda, A., Wakabayashi, M., Sarentonglaga, B., Yamaguchi, M., Hara, A., Fukumor, R. and Nagao, Y. 2015. Glutathione supplementation to semen extender improves the quality of frozen-thawed canine spermatozoa for transcervical insemination. J. Reprod. Develop., 61: 116-122.

Olar, T.T., Brown, R.A. and Picket. B.W. 1989. Influence of extender, cryopreservative and seminal processing procedures on post-thaw motility of canine spermatozoa frozen in straws. Theriogenology., 31: 451-461.

Pantano, T., Mello, M.R., Garcia, J.F. and Visintin, H.J. 2000. Effect of cryoproectant and plunging temperature in liquid nitrogen on the in vitro and in vivo development of morine morculae. Brazil J. Vet. Res. Anim. Sci., 37: 1413-1424.

Pefia, A., Barrio, F., Quintela, L.A. and Herradon, P.G. 1999. Effect of different treatments on frozen thawed dog sperm longevity and acosomal integrity. Theriogenology, 50: 163174.

Pena, A., Lugilde, L.L., Barrio, M., Herradon, P.G. and Quintela, L.A. 2003. Effects of Equex from different sources on post-thaw survival, longevity and intracellular calcium ion concentration of dog spermatozoa. Theriogenology, 59: 1725-1739.

Pereira, S.M., Rossi, A.R. and Alcell, M. 2002. In vitro viability of canine spermatozoa frozen in tris-fructose citric acid extender with ethylene glycol. Ciencia Rural., 32: 649-655.

Petrinkina, A.M., Radcke, S., Guinzel, A.R., Harrison, R.A.P. and Topfer, P. 2004. Role of potassium channels the sodium potassium pump and the cytoskelton in control of dog sperm volume. Theriogenology, 61: 34-54.

Phelps, M.J., Liu, J., Benson, J.D., Willonghby, C.E., Gilmore, J.A. and Crister, J.K. 1999. Effect of percoll separation, cryoprotective agent, and temperature on plasma membrane permeability characteristic of murine spermatozoa and their relevance to cryopreservation. Biol. Reprod., 61: 1031-1041.

Ponglowhapan, S., Gustavsson, B.E. and Forsberg, C.L. 2004. Influence of glucose and fructose in the extender during long term storage of chilled canine semen. Theriogenology, 62: $1498-1517$ 
Romagnoli, S. and Lopate, C. 2014. Transcervical artificial insemination in dogs and cats.review of the technique and practical aspects. Reprod. Domes. Anim., 49(4): 56-63.

Rota, A., Milani, C., Capianca, G. and Martiri, N. 2006. Comparison between glycerol and ethylene glycol for dog semen cryopreservation. Theriogenology, 65: 1848-1858.

Sahoo, S., Kataria, M. and Maiti, S K. 2015. Isolation and characterization of Stromelysin-3 (MMP-11) like protein from a case of mammary carcinoma in a dog. J. Anim. Res., 49(1): 127-131

Said, T.M, Gaglani, A. and Agarwal, A. 2010. Implication of apoptosis in sperm cryoinjury. Reprod. Biomed., 21: 456-62.

Samoylova, T.I., Cox, N.R. and Cochran A.M. 2010 . ZP-binding peptides identified via phage display stimulate production of sperm antibodies in dogs. Anim. Reprod. Sci., 120(1-4): $151-7$.

Serafini, R., Varner, D.D., Bisset, W.J., Blachard, T.L., Teague, S.R. and Love, C.C. 2017. The effect of flashfreezing temperature on stallion sperm DNA structure. Theriogenology, 95: 113-117.

Shalini, I., Antoine, D., Murugavel, K., Kantharaj, S. and Raju, M.S. 2018. Testicular Volume, Seminal Attributes and Body condition score in Infertile Dogs. Int. Curr. Microbiol. Appl. Sci., 7(6): 455-46.

Shalini, I. and Antoine, D. (2018). Semen Characteristics in German Shepherd Dogs. Int. J.Curr. Microbiol. Appl. Sci., 7(03): 2304-2312.

Sharma, P., Jha, A.B., Dubey, R.S. and Pessarakli, M. 2012. Reactive oxygen species,oxidative damage, and antioxidative defense mechanism in plants under stressful conditions. $J$. Bot., 2: 1-26

Shen, H.M., Chia, S.E. and Ong, C.N. 1999. Evaluation of oxidative DNA damage in human sperm and its association with male infertility. J. Androl., 20: 718-723.

Sieme, H., Oldenhof, H. and Wolkers, W.F. 2016. Mode of action of cryoprotectants for sperm preservation. Ani. Reprod. Sci., 169: $2-5$.

Silva, A.R., Cardoso, R.C.S., Uchoa, D.C. and Silva, L.D.M. 2003. Quality of canine semen submitted to single or fractionated glycerol addition during the freezing process. Theriogenology., 59: 821-829.

Silva, I.D.M. and Verstegen, J.P. 1995. Comparisons between three different extenders for canine intrauterine insemination with frozen thawed spermatozoa. Theriogenology, 44: 571579.

Singh, N.P., Muller, C.H. and Berger, R.E. 2003. Effect of age on DNA double strand break and apoptosis in human sperm. Fertil. Steril., 80: 1420-1430.
Slaweta, R., Waşowicz, W. and Laskowska, T. 1988. Selenium content, glutathione peroxidase activity, and lipid peroxide level in fresh bull semen and its relationship to motility of spermatozoa after freezing-thawing. J. Vet. Med. Seri. A., 35: 455-460.

Smith, F.O. 1984. Cryopreservation of canine semen : Technique and performance. Ph.D. Thesis, University of Minnesota.

Storrey, B.T., Noiles, E.E. and Thomson, K.A. 1998. Comparisons between glycerol and polyols, the halose and raffinose to provide a defined cryoprotectant medium for mouse sperm cryopreservation. Cryobiology, 37: 46-58.

Strom, H.B., Larsson, B. and Linde-Forsberg, C. 1997. In vitro characteristics of canine spermatozoa subjected to two methods of cryopreservation. Theriogenolog, 48: 247-256.

Stuart, C.C., Vaughan, J.L., Kershaw, C.M., De Graaf, S.P. and Bathgate, R. 2019. Effect of diluent type, cryoprotectant concentration, storage method and freeze/thaw rates on the post-thaw quality and fertility of cryopreserved alpaca spermatozoa. Scientific Reports., 9(1): 1-8.

Thomassen, R. and Farstad, W. 2009. Artificial insemination in canins. a useful tool in breeding and conservation. Theriogenology, 71: 190-199.

Thundathil, J., Palasz, A.T., Barth, A.D. and Mapletoft, R. 2002. Plasma membrane and acrosomal integrity in bovine spermatozoa with the knobbed acrosomes effect. Theriogenology, 58: 87-102.

Umamageswari, J. 2005. Effect of different methods of cryopreservation on the freezability of canine spermatozoa. M.V.Sc. Thesis submitted to TANUVAS. Chennai-51.

Verstegen, J.P., Onclin, K. and Quada, M.I. 2005. Long term motility and fertility conservation of chilled canine semen using egg yolk added Tris-glucose extender in vivo and in vivo studies. Thereiogenology, 64: 720-733.

Ward, W.S. and Zalensky, A.O. 1996. The unique complex organization of the transcriptionally silent sperm chromatincritical. Rev. Eukary. G. express, 6: 139-147.

Watson, P. 2000. The causes of reduced fertility with cryopreserved semen. Anim. Reprod. Sci., 60-61: 481-492.

Watson, P.F. 1979. The preservation of semen in mammals. Oxford Rev. Reprod. Biol., 1: 283-350.

Wdowiak, A., Bakalczuk, S. and Bakalczuk, G. 2015. The effect of sperm DNA fragmentation on the dynamics of the embryonic development in intracytoplasmatic sperm injection. Reprod. Biol., 5: 94-100.

Yildiz, C., Kay, A., Aksoy, M. and Tekeli, T. 2000. Influence of sugar supplementation of the extender on motility, viability and acrosomal integrity of dog spermatozoa during freezing. Theriogenology, 54: 579-585. 
